\title{
Prediction of roll separating force in a roll pass design of micro-alloyed steel rods
}

\author{
T. El-Bitar, M. El-Meligy \& E. El-Shenawy \\ Plastic Deformation Department, Central Metallurgical R\&D Institute \\ (CMRDI), Egypt
}

\begin{abstract}
The aim of the present work is to validate a constitutive model for the prediction of roll force during rebar steel processing. Roll force is considered as an important segment in the process of design dog bone and slit pass grooves. Actual readings from the industrial rolling field were fed to the model to verify the precision of calculation by model. During the rolling process, the steel section changes from pass to pass, i.e. round-oval-round. The contact angle between the stock and roll ram was divided into six equal segments instead of a complicated process. The model is based on two dimensional plane strain deformation. The contact area is divided into six zones with the same angles dimension. Width, height, velocity, coefficient of friction, strain, strain rate, flow stress and finally rolls separating force are calculated at each of the six points on the roll surface. Mean values for each pass can then be numerically calculated. The coefficient of friction is computed as a function of temperature as well as velocity. Shida's constitutive equation and its modification by Y. Lee are used to calculate the flow stress $\mathrm{Nb}-\mathrm{V}$-micro-alloyed steel. Calculated flow stress increases continuously with the increase of both strain and strain rate. On verification of results, it is noticed that measured flow stresses are higher than that calculated by a value ranging 30-40 MPa. Inside the roll gap, both flow stress and roll separating force show a steep increase with the increase of the contact angle, and the highest values are obtained at the outgoing point.
\end{abstract}

Keywords: bar rolling, separating roll force, flow stress, strain rate, accumulative strain, contact angle, round-oval roll pass. 


\section{Introduction}

Great attention has been paid to the development of models dealing with flat rolling [1-5]. Less data are available on a modeling of bar hot rolling, due to the tedious and complex integrations involved. However, it is important to construct such a model for the development of bar rolling operations.

Obtaining a full analytical solution for the roll force has been one of the most difficult problems in the analysis of groove rolling because of the difficulties in formulating the governing differential equation dealing with the threedimensional deformation. There have been attempts to develop a simplified analytical method as an alternative, Lee and Kim [6] reduced the threedimensional problem into a two-dimensional one by introducing the concept of a weak plane-strain deformation condition.

During the rolling process the steel section changes from round to oval and oval to round. The process involves several passes. To simplify computation in the model, an equivalent rectangle section which was suggested by Lee and Rim, [6] was used (Figure 2). The contact angle between the stock and roll ram was divided into six equal segments instead of complication process.

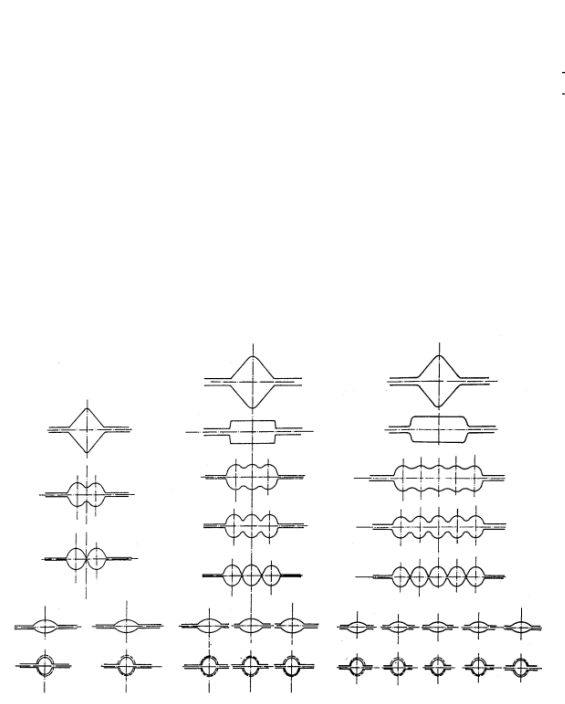

Figure 1: Roll pass design for slitting billet into two, three and five separate rebars [7].

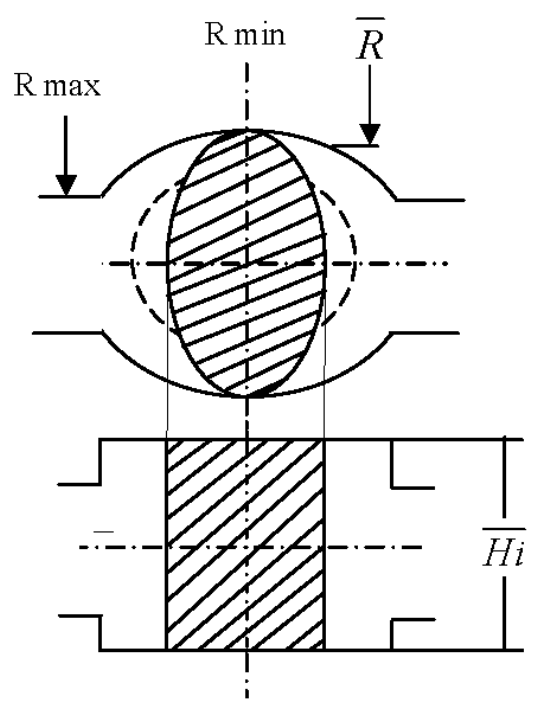

Figure 2: Oval-round pass approximated by rectangular section. 


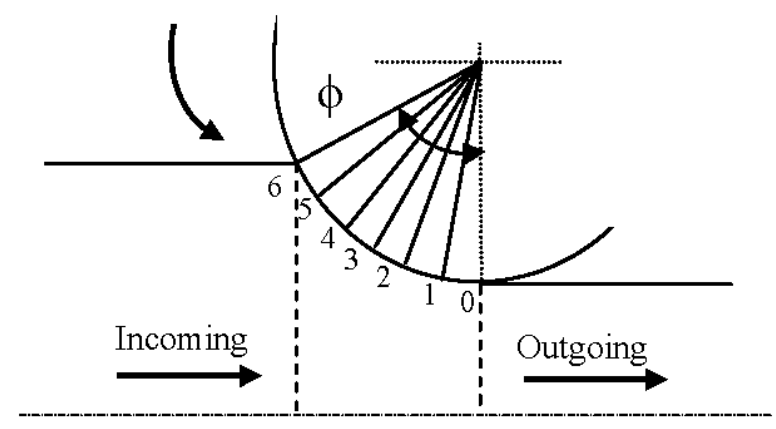

Figure 3: Dividing of the contact angle.

\subsection{Roll force calculation}

The roll force was calculated using the following equation.

$$
F_{\text {rod }}=P_{\text {rod }} A_{d}
$$

where

$\mathrm{F}_{\text {rod }}=$ roll force for round-oval-round deformation;

$\mathrm{P}_{\text {rod }}=$ the average contact stress applied to the work piece;

$\mathrm{A}_{\mathrm{d}}=$ the projected contact area.

With the assumption of plane-strain deformation condition, the average contact stress in an oval-round (or round-oval) pass can be formulated as [6]:

$$
P_{r o d}=\left(1-\varepsilon_{1}\right) \sigma_{f} \exp \left[\frac{\mu \bar{L}}{\overline{h_{m}}}\right]
$$

where

$\varepsilon_{1}=$ Principal plastic strain along the $x$-axis;

$\sigma_{\mathrm{f}}=$ flow stress of steels at the pass conditions;

$\mu=$ Coefficient of friction during hot rolling and can be calculated by the formula developed by El Bitar [8]

$$
\mu=1.05 K-\left(0.0005^{*} \mathrm{~T}\right)-\left(0.056^{*} \mathrm{~V} / 1000\right)
$$

$\mathrm{K}=1$ for the steel rolls;

$\mathrm{T}=$ temperature of the work-piece should not be less than $700^{\circ} \mathrm{C}$; and

$\mathrm{V}=$ velocity $(\mathrm{mm} / \mathrm{sec})$ and not more than $5000 \mathrm{~mm} / \mathrm{sec}$;

$\bar{L}=$ The effective projected contact length (defined in the Appendix). 


\subsection{Principal accumulative plastic strain}

Principal accumulative plastic strain at any point (n) on the arc of contact along the $x$-axis, $[1,9]$ is expressed as

$$
\varepsilon_{1 n}=\left[\ln \left(\frac{\overline{W_{\mathrm{i}}}}{\overline{W_{p}}}\right)+\varepsilon_{1(n-1)}\right] *\left[1-\left(\frac{(6-n)^{2}}{36}\right)\right]
$$

where, $\mathrm{n}=0,1,2,3 \ldots \ldots, 6$;

$\bar{W}_{i}$ : equivalent width of incoming bar;

$\bar{W}_{p}$ : equivalent width of outgoing bar.

Similarly the principal accumulative plastic strain at any point (n) on the arc of contact along the $y$-axis, $[1,9]$ is expressed as;

$$
\varepsilon_{2 n}=\left[\ln \left(\frac{\bar{H}_{i}}{\bar{H}_{p}}\right)+\varepsilon_{2(n-1)}\right] *\left[1-\left(\frac{(6-n)^{2}}{36}\right)\right]
$$

\subsection{Flow stress constitutive equation}

Flow stress constitutive formulae is based on experimental data proposed by Shida et al. [11] and developed later by Lee et al. [10]. Flow stress is expressed as follows:

$$
\sigma_{f}=\sigma d\left(C_{e q}, T\right) f w(\bar{\varepsilon}) f r(\dot{\bar{\varepsilon}})
$$

where

$\sigma_{d}\left(C_{e q}, T\right)$ deformation resistance function;

$f_{w}(\bar{\varepsilon}) \quad$ strain hardening function;

$f_{r}(\dot{\bar{\varepsilon}}) \quad$ strain rate hardening function.

The 3 functions consist the $\sigma_{\mathrm{f}}$ are calculated as

\subsubsection{Deformation resistance function}

Deformation temperature is normalized and expressed as

$$
T\left({ }^{\circ} K\right)=\frac{T\left({ }^{\circ} C\right)+273}{1000} .
$$

At the same time, a temperature term is defined which depends on the value of carbon equivalent and can be defined as 


$$
T_{p}=0.95 \frac{C_{e q}+0.41}{C_{e q}+0.32} .
$$

If the normalized temperature $\mathrm{T}\left({ }^{\circ} \mathrm{K}\right)$ is greater than the temperature term $\mathrm{T}_{\mathrm{p}}$ then the deformation function is expressed as follows

$$
\sigma_{d}=0.28 \exp \left(\frac{5.0}{T}-\frac{0.01}{C_{e q}+0.05}\right)
$$

However, if $\mathrm{T}\left({ }^{\circ} \mathrm{K}\right)$ is less than $\mathrm{T}_{\mathrm{p}}$ indicating that the phase transformation occurs. The flow stress is then expressed as;

$$
\sigma_{d}=0.28\left[g\left(C_{e q}, T\right)\right] *\left[\exp \left(\frac{C_{e q}+0.32}{0.19\left(C_{e q}+0.41\right)}-\frac{0.01}{C_{e q}+0.05}\right)\right]
$$

where, $\mathrm{g}(\mathrm{C}, \mathrm{T})$ in Eq. (10) is expressed as

$$
g\left(C_{e q}, T\right)=30.0\left(C_{e q}+0.9\right)\left[T-0.95 \frac{C_{e q}+0.49}{C_{e q}+0.42}\right]^{2}+\frac{C_{e q}+0.06}{C_{e q}+0.09} .
$$

\subsubsection{Strain hardening function}

The second term of the flow stress constitutive equation is the strain hardening function which can be expressed as:

$$
f w(\bar{\varepsilon})=1.3\left(\frac{1}{0.2} \bar{\varepsilon}\right)^{n}-0.3\left(\frac{1}{0.2} \bar{\varepsilon}\right)
$$

where

$$
n=0.41-0.07 C_{e q}
$$

Eq. (12) shows that the flow stress starts to increase when the strain becomes higher than 0.2, which is the reference strain for work hardening. Eq. (13) implies that work hardening was modeled as a function of carbon content only and it does not vary with temperature and strain rate.

\subsubsection{Strain rate hardening function}

The principal plastic strain along the $y$-axis can be expressed as:

$$
\varepsilon_{2}=\ln \left(\frac{H_{i}}{H_{p}}\right) \text {. }
$$


Then, the mean effective strain at a given pass, $\bar{\varepsilon}$, is:

$$
\bar{\varepsilon}=\frac{2}{\sqrt{3}} \varepsilon_{2} \sqrt{\left[1+\left(\frac{\varepsilon_{1}}{\varepsilon_{2}}\right)^{2}+\left(\frac{\varepsilon_{1}}{\varepsilon_{2}}\right)\right]}
$$

and the strain rate $\dot{\bar{\varepsilon}}$ can be computed as

$$
\stackrel{-}{\varepsilon}=\frac{\bar{\varepsilon}}{t}
$$

where $\mathrm{t}$ represents time during the pass rolling and can be computed as

$$
t=\frac{2 \pi N \bar{R}}{60 \bar{L}} .
$$

Then the strain rate hardening function $f_{r}(\stackrel{\bullet}{\varepsilon})$ can be calculated as Shida [10] proposed

$$
f r(\dot{\bar{\varepsilon}})=\left(\frac{1}{10} \frac{\bullet}{\varepsilon}\right)^{m}
$$

According to Shida, (Eq. (18)) implies that the flow stress starts to increase rapidly when the strain rate of material is higher than 10 .

The coefficient of strain rate sensitivity, $\mathrm{m}$, is defined either as:

$$
m=\left(-0.019 C_{e q}+0.126\right) T+\left(0.076 C_{e q}-0.05\right) \text { for } \quad T>T_{p}
$$

or

$$
m=\left(0.081 C_{e q}-0.154\right) T+\left(-0.019 C_{e q}+0.207\right)+\frac{0.027}{C_{e q}+0.32} \text { for } T \leq T_{p} .
$$

Eq. (20) illustrates that strain rate sensitivity is depending on carbon content and temperature. Eq. (20) is applicable up to $\bar{\varepsilon}=100 \mathrm{~s}^{-1}$, [11].

Lee modified the strain rate hardening function [10] so that it can reflect the effect of strain rate on the flow stress when the strain rate exceeds $100 \mathrm{~s}^{-1}$ as follows

$$
f r(\dot{\bar{\varepsilon}})=\left(\frac{1}{10} \dot{\bar{\varepsilon}}\right)^{m}\left(\frac{1}{100} \dot{\bar{\varepsilon}}\right)^{m / 2.4}\left(\frac{1}{1000} \dot{\bar{\varepsilon}}\right)^{m / 15}
$$

The second and third terms in the right side of Eq. (21) reflect the flow stress increment when the strain rate exceeds 100 and $1000 \mathrm{~s}^{-1}$, respectively. 
Accordingly, the coefficient of strain rate sensitivity, $\mathbf{m}$, is the same in Eqs. (19) and (20).

The carbon equivalent in case of microalloyed steel can be calculated using the following equation

$$
C_{e q}=[C]+\frac{[\mathrm{Mn}]}{6}+\frac{[\mathrm{Cr}]+[\mathrm{V}]+[\mathrm{Nb}]}{12}
$$

which takes into account the contributions of $\mathrm{Mn}, \mathrm{Cr}, \mathrm{V}$ and $\mathrm{Nb}$ to the resistance of the steel to deformation.

\section{Processing conditions}

The steel under investigation is $\mathrm{Nb}-\mathrm{V}$-micro-alloyed steel. The initial billet cross-section is $150 \times 150 \mathrm{~mm}$. Table 1 shows the steel chemical composition.

Table 1: Chemical composition of the steel.

\begin{tabular}{|c|c|c|c|c|c|c|c|}
\hline Element & $\mathrm{C}$ & $\mathrm{Mn}$ & $\mathrm{Si}$ & $\mathrm{S}$ & $\mathrm{P}$ & $\mathrm{Nb}$ & $\mathrm{V}$ \\
\hline $\mathrm{Wt} \%$ & 0.08 & 1.3 & 0.4 & 0.008 & 0.015 & 0.05 & 0.08 \\
\hline
\end{tabular}

As an example, Table 2 summarizes measured processing data of the last 15 constitutive rolling passes for a final rod diameter of $16.1 \mathrm{~mm}$.

Table 2: Processing conditions.

\begin{tabular}{|c|c|c|c|c|c|c|}
\hline \multirow[t]{2}{*}{$\begin{array}{c}\text { Pass } \\
\#\end{array}$} & \multirow[t]{2}{*}{$\begin{array}{c}\text { Incoming } \\
\text { shape }\end{array}$} & \multicolumn{2}{|c|}{$\begin{array}{c}\text { Incoming } \\
\text { dimension, } \mathrm{mm}\end{array}$} & \multirow{2}{*}{$\begin{array}{c}\text { Incoming } \\
\text { velocity, } \\
\mathrm{m} / \mathrm{s}\end{array}$} & \multirow{2}{*}{$\begin{array}{c}\text { Pass } \\
\text { temp., } \\
{ }^{\circ} \mathrm{C}\end{array}$} & \multirow{2}{*}{$\begin{array}{c}\text { Max. } \\
\text { Rolling } \\
\text { diameter, } \\
\text { mm }\end{array}$} \\
\hline & & W & $\mathrm{H}$ & & & \\
\hline 7 & Oval & 74 & 113 & 0.23 & 994 & 520 \\
\hline 8 & Round & 84 & 84 & 0.30 & 982 & 520 \\
\hline 9 & Oval & 57 & 92 & 0.39 & 981 & 520 \\
\hline 10 & Round & 65.5 & 65.5 & 0.49 & 946 & 520 \\
\hline 11 & Oval & 43 & 74 & 0.64 & 951 & 425 \\
\hline 12 & Round & 51.2 & 51.2 & 0.80 & 945 & 425 \\
\hline 13 & Oval & 33.5 & 59 & 1.08 & 954 & 425 \\
\hline 14 & Round & 40 & 40 & 1.31 & 938 & 425 \\
\hline 15 & Oval & 25 & 48 & 1.73 & 954 & 425 \\
\hline 16 & Round & 31.2 & 31.2 & 2.16 & 959 & 425 \\
\hline 17 & Oval & 19 & 39 & 2.81 & 978 & 325 \\
\hline 18 & Round & 24.4 & 24.4 & 3.53 & 966 & 325 \\
\hline 19 & Oval & 14 & 33 & 4.64 & 997 & 325 \\
\hline 20 & Round & 19 & 19 & 5.82 & 1015 & 325 \\
\hline 21 & Oval & 13 & 24 & 6.92 & 1028 & 325 \\
\hline
\end{tabular}




\section{Model calculations, results and discussions}

The present model is applied on last 15 constitutive rolling passes for calculation of roll separating force at each pass. Table 3 shows some calculated values for a particular case.

Fig. 4 represents the calculated flow curves of rolled steel under processing with different strain rates in the temperature range $950-1000^{\circ} \mathrm{C}$. It is clear that the flow stress increases continuously with the amount of strain showing a logarithmic behavior.

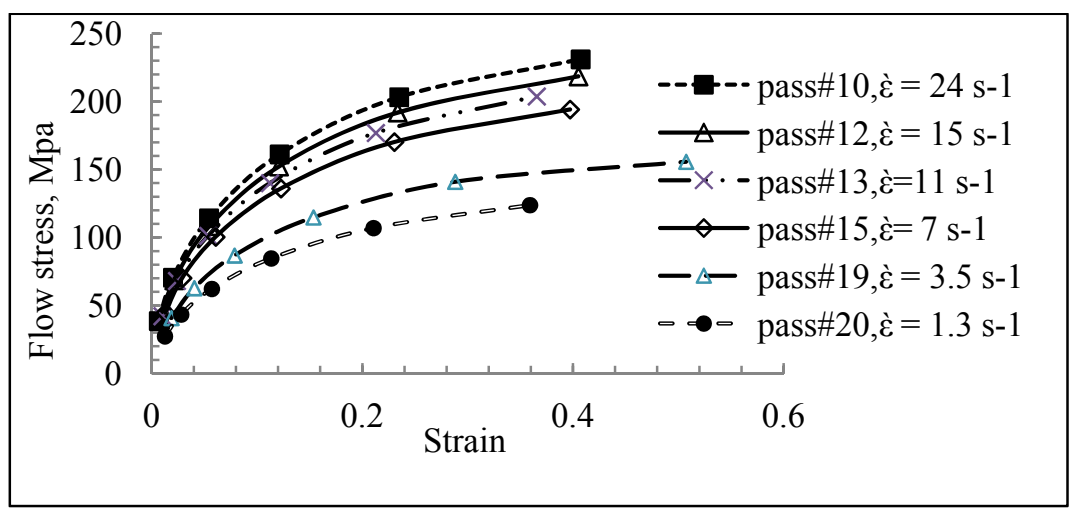

Figure 4: Effect of strain on flow stress for different strain rate (temperature range $950-1000^{\circ} \mathrm{C}$ ).

Similarly, the flow stress increases (with a power function ) with the increase of strain rate as shown in Fig. 5 reflecting an increase in resistance to deformation with the increase of deformation speed [5].

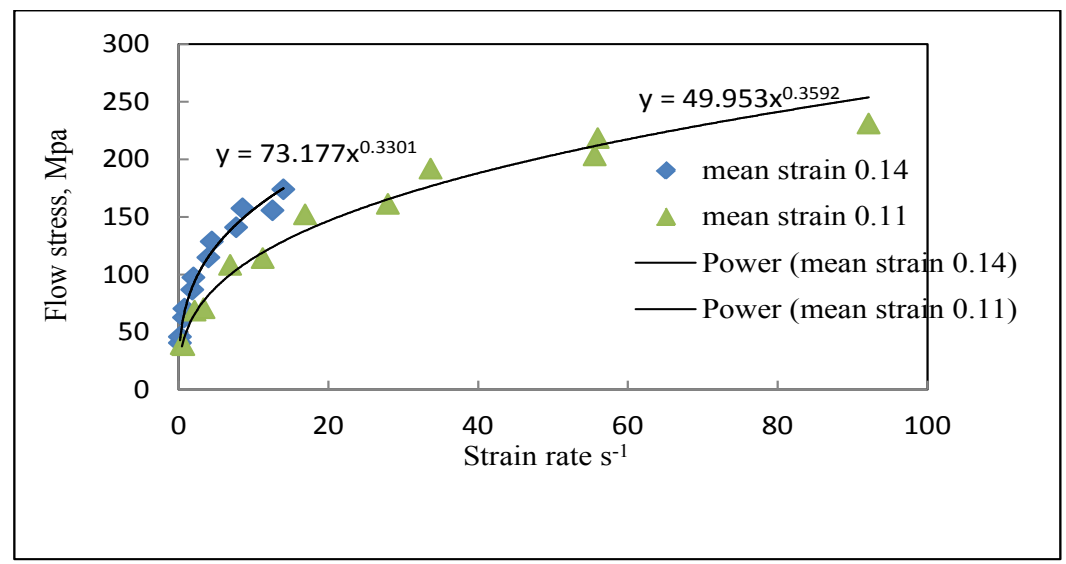

Figure 5: Effect of strain rate on flow stress for different strain (temperature range $950-1000^{\circ} \mathrm{C}$ ). 
High Performance and Optimum Design of Structures and Materials 75

\begin{tabular}{|c|c|c|c|c|c|c|c|c|c|c|c|c|c|c|c|c|}
\hline 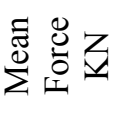 & & $\begin{array}{l}\bar{a} \\
\infty \\
\infty \\
\end{array}$ & 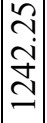 & 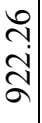 & \begin{tabular}{l}
\multirow{2}{n}{} \\
$\infty$ \\
\hdashline$a$
\end{tabular} & 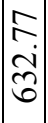 & $\begin{array}{l}n \\
n \\
n \\
n\end{array}$ & $\begin{array}{l}\text { ñ } \\
\text { } \\
\text { m}\end{array}$ & & $\mid \begin{array}{l}\infty \\
\sigma \\
\bar{b} \\
\sim\end{array}$ & $\begin{array}{l}\overline{0} \\
\dot{x} \\
\sim\end{array}$ & \begin{tabular}{l}
$\infty$ \\
$n$ \\
\multirow{I}{\Xi}{} \\
-
\end{tabular} & $\begin{array}{l} \pm \\
\vdots \\
6 \\
-\end{array}$ & & $\begin{array}{l}\text { ô. } \\
\text { ț }\end{array}$ & 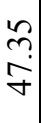 \\
\hline 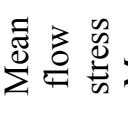 & & $\mid \begin{array}{c}\infty \\
\mathfrak{1} \\
\vdots \\
0 \\
-1\end{array}$ & 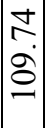 & $\begin{array}{l}\hat{\sigma} \\
\dot{0} \\
0\end{array}$ & $\begin{array}{l}0 \\
= \\
=\end{array}$ & $\begin{array}{l}\stackrel{\Xi}{ } \\
\check{n} \\
\beth\end{array}$ & $\begin{array}{l}\mathscr{6} \\
\check{z} \\
=\end{array}$ & $\begin{array}{l}n \\
0 \\
\vdots \\
0\end{array}$ & $\begin{array}{l}\bar{a} \\
\hat{0} \\
=\end{array}$ & $\mid \begin{array}{c}\infty \\
0 \\
0 \\
0 \\
-\end{array}$ & $\begin{array}{l}n \\
a \\
\infty \\
a\end{array} \mid$ & & & & & $\begin{array}{l}\vec{\nabla} \\
\dot{J}\end{array}$ \\
\hline 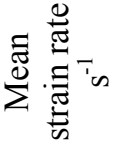 & & $\begin{array}{l}\stackrel{a}{+} \\
\dot{q} \\
\dot{q}\end{array}$ & $\frac{\dot{v}}{\dot{Z}}$ & $\begin{array}{l}\infty \\
\infty \\
\grave{\lambda}\end{array}$ & $\begin{array}{l}0 \\
\stackrel{+}{\sim}\end{array}$ & 命 & $\begin{array}{l}\infty \\
0 \\
\dot{ \pm} \\
-\end{array}$ & $\begin{array}{l}\hat{0} \\
= \\
\end{array}$ & $\left|\begin{array}{l}\infty \\
\infty \\
\infty \\
\infty\end{array}\right|$ & $\frac{0}{2}$ & & & & $\begin{array}{l}\tilde{\sigma} \\
\dot{r}\end{array}$ & $\stackrel{?}{-}$ & $\left(\begin{array}{l}\infty \\
\sim \\
-\end{array}\right.$ \\
\hline 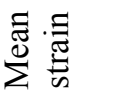 & & $\begin{array}{l}\infty \\
0 \\
0 \\
0\end{array}$ & $\mid \begin{array}{l}0 \\
\ddot{0}\end{array}$ & $\begin{array}{l}2 \\
0 \\
0\end{array}$ & $=$ & $\stackrel{0}{0}$ & $=$ & 음 & $\frac{1}{3}$ & $\exists$ & $\frac{N}{0}$ & $\frac{1}{0}$ & $\overrightarrow{ \pm}$ & $\stackrel{ \pm}{\circ}$ & $\begin{array}{c}0 \\
\\
0\end{array}$ & 옴 \\
\hline$\sum_{\Sigma}^{\Xi}=$ & & n.n. & ? & ڤn & 吕 & ñ & 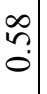 & ñ & $\mid \begin{array}{c}\infty \\
n \\
0\end{array}$ & 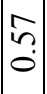 & $\tilde{n}$ & ?ֶ. & $n$ & $\begin{array}{l}n \\
n \\
0\end{array}$ & 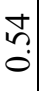 & 帒 \\
\hline 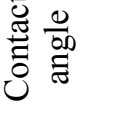 & & $\bar{n}$ & సุ. & సุ. & ก̦. & $\mid \begin{array}{c}0 \\
\cdots \\
0\end{array}$ & స్ & กิ & ָั๋ & 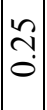 & กิ & ָิ & స̂. & ஸे. & ㅁ. & ํㅗ \\
\hline 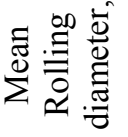 & & 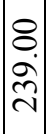 & 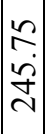 & $\begin{array}{c}\tilde{\sigma} \\
\dot{\sigma} \\
\stackrel{+}{\sim}\end{array}$ & $\begin{array}{l}n \\
\mathfrak{a} \\
\mathfrak{d} \\
\text { ปn }\end{array}$ & $\mid \begin{array}{l} \\
2 \\
2 \\
-\end{array}$ & \begin{tabular}{l}
$m$ \\
\hdashline \\
$\stackrel{0}{0}$
\end{tabular} & $\begin{array}{c}0 \\
n \\
\text { ç } \\
\text { กิ }\end{array}$ & 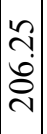 & 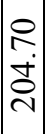 & 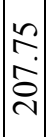 & 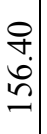 & $\mid \begin{array}{l}8 \\
0 \\
2 \\
-1\end{array}$ & $\begin{array}{l}n \\
r \\
i n \\
-\end{array}$ & กิ & $\mid \begin{array}{c}\infty \\
+ \\
\infty \\
n \\
-\end{array}$ \\
\hline 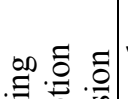 & $\simeq$ & $\begin{array}{l}n \\
n \\
\infty \\
\infty\end{array}$ & $\begin{array}{l}\hat{a} \\
1 \\
6\end{array}$ & î & $\frac{8}{\dot{f}}$ & $\mid$\begin{tabular}{c}
$\sim$ \\
\hdashline \\
$\infty$ \\
$n$
\end{tabular} & 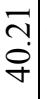 & $\mid \begin{array}{l}4 \\
m \\
o \\
+ \\
\end{array}$ & $\frac{\stackrel{\sim}{f}}{m}$ & $\begin{array}{l}\frac{0}{2} \\
\frac{1}{n}\end{array}$ & $\begin{array}{l}\stackrel{0}{n} \\
\stackrel{ \pm}{ \pm}\end{array}$ & $\begin{array}{l}\hat{b} \\
\dot{0} \\
\tilde{n}\end{array}$ & $\mid \begin{array}{c}0 \\
-2 \\
-2\end{array}$ & 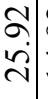 & $\begin{array}{l}\tilde{\sigma} \\
\dot{\Xi}\end{array}$ & $\left|\begin{array}{l}2 \\
\infty \\
\infty \\
-\end{array}\right|$ \\
\hline$\Xi \begin{array}{l}\tilde{E} \\
\mathbb{E}\end{array}$ & 3 & $\stackrel{ \pm}{\sim}$ & 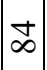 & in & $\begin{array}{l}n \\
n \\
6\end{array}$ & $\stackrel{m}{\forall}$ & $\frac{n}{n}$ & $\begin{array}{l}n \\
m \\
m\end{array}$ & 아 & $\approx$ & $\frac{N}{m}$ & 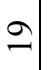 & $\stackrel{+}{\dot{\sim}}$ & \pm & 2 & $m$ \\
\hline 䜦 \# & & $r$ & $\infty$ & $a$ & $\stackrel{0}{-1}$ & 二 & $\simeq$ & $\approx$ & $\Xi$ & $\because$ & 0 & 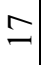 & $\infty$ & 2 & ㄱ. & $\bar{\sim}$ \\
\hline
\end{tabular}


To verify the model accuracy for flow stress completeness, comparison between the calculated and measured flow stresses at specified strain rates has been done. Fig. 6 presents the required comparison at 7, 11, and $24 \mathrm{Sec}^{-1}$ strain rates. Both calculated and measured flow curves show logarithmic behavior. However, the measured flow stresses are higher than the calculated ones by 30 to $40 \mathrm{MPa}$, which may lead to the conclusion that Shida's model needs further development.

The contact angle of the roll gap for pass \#10 is divided into 6 equal portions. Fig. 7 presents calculated results at each point on the roll gap for both flow stress and roll separating force.

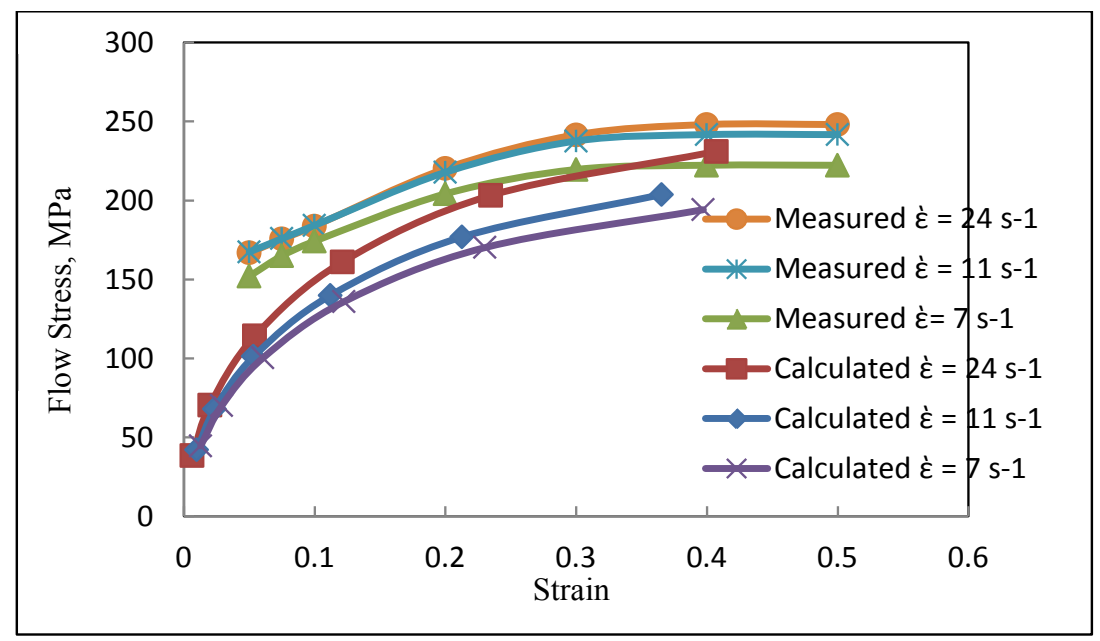

Figure 6: Comparison between measured and calculated flow stress at different strain rates.

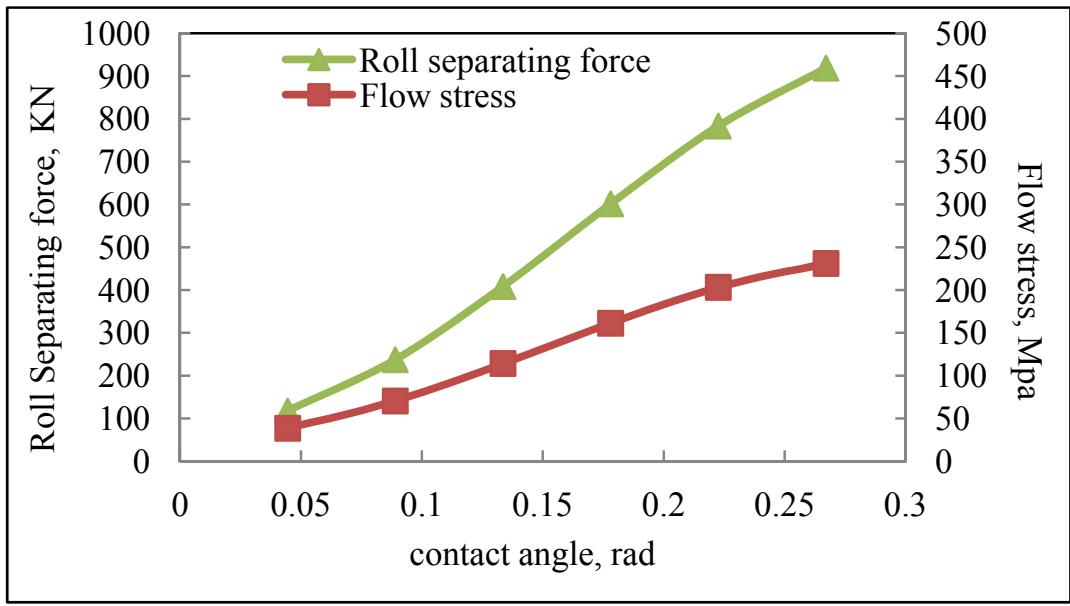

Figure 7: Variation of separating roll force and flow stress inside the roll gap for pass \#10. 
Both curves show a steep increase with the increase of the contact angle. The highest values are obtained at the outgoing point on the roll gap, due to cumulative strain from the incoming point to the outgoing one.

Fig. 8 represents the roll separating force profile in each pass with different strain rates. The roll separating force increases continuously with the increase of strain as the deformation continues between the rolls. The rate of increase of the roll separating force begins very high pass \#10, then slows down at the subsequent passes, as the strain rate decreases. The highest values are obtained at the outgoing point on the roll gap.

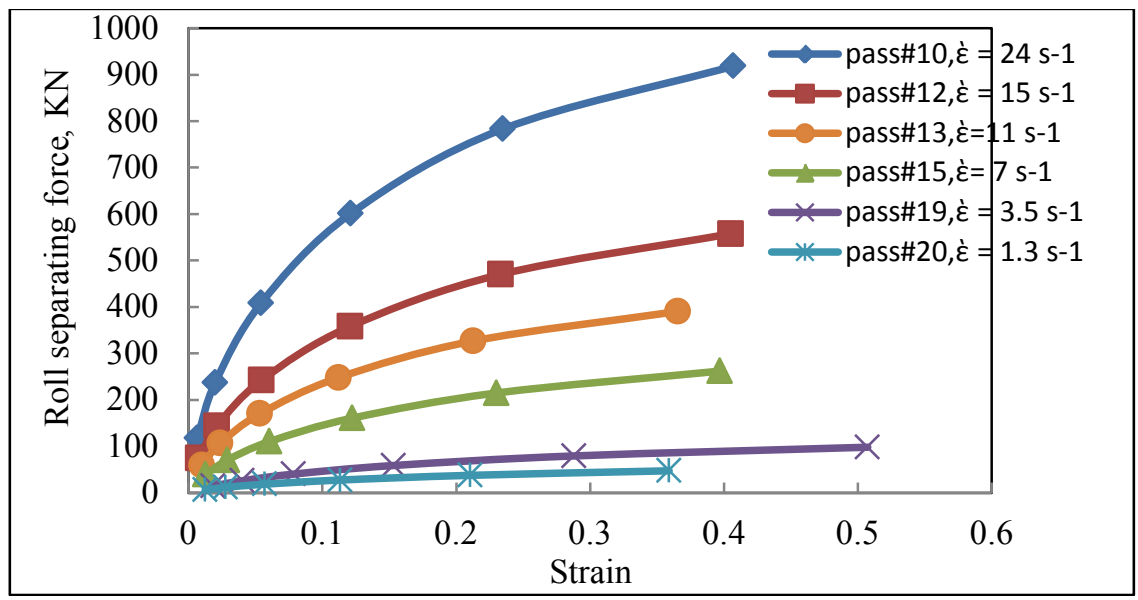

Figure 8: Influence of strain on roll separating force for different strain rates (temperature range $950-1000^{\circ} \mathrm{C}$ ).

\section{Conclusions}

The work presented in this paper refers to the construction and experimental validation of an integrated model to predict the roll force in rebar steel rolling.

The model uses equivalent rectangular section approximation to represent round and oval sections. The contact angle has been divided into six equal portions, to calculate the mean values of width, height, velocity, coefficient of friction, strain, strain rate, flow stress and roll separating force for each pass.

The results found had the following conclusions,

- Flow stress increases continuously with the increase of both strain and strain rate.

- Measured flow stresses are higher than the calculated ones with a value ranging 30 to $40 \mathrm{MPa}(\%)$.

- Both flow stress and roll separating force show step increase with the increase of the contact angle on the roll gap, and the highest values are obtained at the outgoing point. 


\section{Appendix}

\section{A.1 Contact angle calculations}

As a first step in the numerical calculation, the contact angle $\alpha$ for each pass is calculated by the following formula

$$
\alpha=\cos ^{-1}\left(1-\frac{\bar{H}_{i}-\bar{H}_{p}}{2 R}\right)
$$

where: $\bar{H}_{i}$ : equivalent height of the incoming work piece;

$\bar{H}_{p}$ : equivalent height of outgoing work piece;

$\mathrm{R}$ : means roll radius.

The contact angle is then divided into six equal portions as shown in Fig 3, where each portion can be treated as a deformation pass. A mean of 6 values for each rolling parameter is calculated by using the analytical Simpson rule as follows

$$
x_{\text {mean }}=\frac{\left(x_{0}+x_{6}\right)+2\left(x_{1}+x_{2}+x_{3}+x_{4}+x_{4}\right)}{12}
$$

where, $x_{n}$ : the rolling parameter at point $(n)$ on the arc of contact.

\section{A.2 Effective projected contact length calculations}

$\bar{L}=$ The effective projected contact length between the grooved roll and the work piece and can be calculated by the following formula.

$$
\begin{gathered}
\bar{L}=\sqrt{\left\{R_{\max }-\frac{1}{2}\left(\bar{H}_{p}-G\right)\right\}\left(\bar{H}_{i}-\bar{H}_{p}\right)} \\
\bar{h}_{m}=\left[\frac{1}{2}\left(\bar{H}_{i}+\bar{H}_{p}\right)\right]
\end{gathered}
$$

where

$\mathrm{R}_{\max }=$ max roll radius;

$\bar{H}_{i}$ : equivalent height of incoming bar;

$\bar{H}_{p}$ : equivalent height of outgoing bar;

$\mathrm{G}=$ Clearance between rolls; and

$\bar{h}_{m=}$ is the effective mean height of the work piece computed by equation (A-4).

\section{References}

[1] El-Bitar, T., A computer program for the calculation of Roll Force and Torque with Strip Tension in Cold Rolling. - Transactions of Iron and Steel Society, 15, 1994. 
[2] El-Bitar, T., Constitutive Modeling and Analysis of Hot Flat Rolling. - 1st European Rolling Conference. And Hungarolling, 12th National Rolling Conference, 4-6 September, Balatonszeplak, Hungary, 96, 1996.

[3] El-Bitar, T., Valuation of Rolling Force and Torque of Steel through Modeling with the aid of Hot Compression Tests - 7th International Conference on Force, Mass and Torque Measurements, Sep. 14-18, Taejon, Republic of Korea, 403-407, 1998.

[4] El-Bitar, T., Role of Compressive flow curves in the evolutionary computing model for hot flat rolling. - La Metallurgia Italiana, 11, 17-20, 1998.

[5] El-Bitar, T., Modification of Roll Pass Design of Low Pearlite, FineGrained Sheet Steel using Numerical Modeling and Processing Maps. Canadian Metallurgical Quarterly, 39, 3, 319-324, 2000.

[6] Lee, Y. Kim, Y.H., Approximate analysis of roll force for round- ovalround pass rolling sequence. - Journal of Materials Processing Technology, 113, 124-130, 2001.

[7] Turczyn, S., Nowakowski, A., Michalowski, M., Roll Pass Design for Ribbed Bars. - Hradec nad Moravicí, METAL 2004, 2004.

[8] El-Bitar, T. et al. Model for prediction of microstructural events during rod hot rolling of austenitic stainless. - Canadian Metallurgical Quarterly, 41, 4, 2002.

[9] Bayoumia, L., Lee, Y., Effect of interstand tension on roll load, torque and work pieced formation in the rod rolling process. - Journal of materials processing technology, 145, 7-13, 2004.

[10] Lee, Y. Kim, B.M. Park, K.J. Seo, S.W. Min, O., A study for the constitutive equation of carbon steel subjected to large strains, high temperatures and high strain rates. - Journal of Materials Processing Technology, 130-131 and 181-188, 2002.

[11] Lenard, J. Pietrzyk, M. Cser, L., Mathematical and Physical Simulation of the Properties of Hot Rolled Products. - Elsevier Science Ltd, The Boulevard, Langford Lane, Kidlington, Oxford OX5 IGB, UK, 1999. 